\title{
Selection of a DNA barcode for Nectriaceae from fungal whole-genomes
}

\author{
ZENG ZhaoQing ${ }^{1,2}$, ZHAO Peng $^{1}$, LUO Jing $^{1}$, ZHUANG WenYing $^{1 *} \&$ YU ZhiHe ${ }^{3}$ \\ ${ }^{1}$ State Key Laboratory of Mycology, Institute of Microbiology, Chinese Academy of Sciences, Beijing 100101, China; \\ ${ }^{2}$ Graduate University of Chinese Academy of Sciences, Beijing 100049, China; \\ ${ }^{3}$ College of Life Sciences, Yangtze University, Jingzhou 434025, China
}

Received October 21, 2011; accepted November 17, 2011

\begin{abstract}
A DNA barcode is a short segment of sequence that is able to distinguish species. A barcode must ideally contain enough variation to distinguish every individual species and be easily obtained. Fungi of Nectriaceae are economically important and show high species diversity. To establish a standard DNA barcode for this group of fungi, the genomes of Neurospora crassa and 30 other filamentous fungi were compared. The expect value was treated as a criterion to recognize homologous sequences. Four candidate markers, $H s p 90, A A C, C D C 48$, and $E F 3$, were tested for their feasibility as barcodes in the identification of 34 well-established species belonging to 13 genera of Nectriaceae. Two hundred and fifteen sequences were analyzed. Intra- and inter-specific variations and the success rate of PCR amplification and sequencing were considered as important criteria for estimation of the candidate markers. Ultimately, the partial $E F 3$ gene met the requirements for a good DNA barcode: No overlap was found between the intra- and inter-specific pairwise distances. The smallest inter-specific distance of $E F 3$ gene was $3.19 \%$, while the largest intra-specific distance was $1.79 \%$. In addition, there was a high success rate in PCR and sequencing for this gene (96.3\%). CDC48 showed sufficiently high sequence variation among species, but the PCR and sequencing success rate was $84 \%$ using a single pair of primers. Although the $H s p 90$ and $A A C$ genes had higher PCR and sequencing success rates ( $96.3 \%$ and $97.5 \%$, respectively), overlapping occurred between the intra- and inter-specific variations, which could lead to misidentification. Therefore, we propose the $E F 3$ gene as a possible DNA barcode for the nectriaceous fungi.
\end{abstract}

barcoding gap, expect value, fungal genomes, homologous sequence, PCR and sequencing success rate, sequence variation

Citation: Zeng Z Q, Zhao P, Luo J, et al. Selection of a DNA barcode for Nectriaceae from fungal whole-genomes. Sci China Life Sci, 2012, 55: 80-88, doi: $10.1007 / \mathrm{s} 11427-012-4266-2$

DNA barcoding, in the strict sense, is defined as the standardized analysis of an easily obtained fragment for sequence-based identification of species [1]. A barcode should have the attributes required for rapid species identification for biodiversity assessment, detection of species invasion, food and feedstuff safety, ecology, natural resources conservation, ornamental fish trade, and human health [2-12]. In the animal kingdom, the mitochondrial cytochrome c oxidase 1 gene is capable of species identification [13-18].

*Corresponding author (email: zhuangwy@im.ac.cn)
In plants, the combination of $r b c L$ and matK [19], psbA-trnH and ITS (internal transcribed spacer) [20] and ITS2 [21,22] are considered as appropriate barcodes. However, recognition of a universal DNA barcode for fungi has been a more challenging task, because many fungi are microscopic, species concepts are inconsistently applied, and some fungi are pleomorphic [23]. In recent years, studies have increasingly focused on fungal DNA barcoding. The ITS region was found to be effective for species discrimination of six genera in Zygomycota [24], Trichoderma and Hypocrea in Ascomycota [25], and the Cortinarius section 
of Calochroi [26], Melampsora [27] and some edible fungi [23] in Basidiomycota. Nevertheless, this region appeared to be problematic in dealing with some closely related species of arbuscular mycorrhizal fungi [1], the blue stain fungi [28], and nectriaceous fungi [29]. Other barcode loci, such as nuclear $28 \mathrm{~S}$ rDNA and translation elongation factor $1 \alpha$ gene, provide a greater capability of species separation in some groups [25,30,31]. Zhao et al. [29] investigated four candidate DNA barcode markers for their feasibility in the identification of some nectriaceous fungi, and the $\beta$-tubulin gene was proposed as a possible barcode. So far, an official DNA barcode for fungi has not been defined [1,32]. In previous studies, the majority of the candidate markers were selected from genes applied to fungal phylogeny.

Since the publication of the first fungal genome, the model yeast Saccharomyces cerevisiae in 1996 [33], more than 400 fungal genome projects have been launched. One hundred and twenty-eight fungal species have been sequenced or partially sequenced [34]. Recent research on fungal genomics have concentrated on phylogeny $[35,36]$, pathogenicity [37,38], antifungal drug discovery [39-41], yeast comparative genomics $[42,43]$, and the search for a DNA barcode $[44,45]$. Comparative genomics has become a powerful and useful tool as datasets increase, and more data are able to discriminate conserved from divergent DNA [46]. Moreover, this approach identified conserved genes that are only found in fungi [42].

Fungi of Nectriaceae are distributed worldwide and occur on various substrates in tropical and subtropical regions [47]. They are economically important, show very high species diversity, and a broad range of lifestyles [48]. Rapid species identification of the group is required for plant disease diagnoses, discovery of new bioactive compounds, exploration of potential biocontrol agents, and protection from harmful mycotoxins [29]. In this study, we compared the genomes of Neurospora crassa and 30 other filamentous fungi, and utilized the expect value ( $E$-value) as a criterion to identify homologous sequences. Among the obtained sequences, four candidate barcode markers were selected and tested for their feasibility as a DNA barcode for the nectriaceous fungi. The genes encode the heat shock protein 90 (Hsp90), the ADP/ATP carrier protein $(A A C)$, the cell division cycle protein $48(C D C 48)$, and the elongation factor $3(E F 3)$.

\section{Materials and methods}

\subsection{Materials studied}

Two hundred and fifteen sequences of four candidate markers, Hsp90, AAC, CDC48, and EF3 genes, from 34 clearly documented and generally accepted species belonging to 13 genera of Nectriaceae were analyzed. All sequences have been deposited in GenBank (Table 1).

\subsection{Genome comparison}

To select a candidate DNA barcode marker, 31 genomes of filamentous fungi (including $16 \mathrm{spp}$. of Eurotiomycetes, 10 of Sordariomycetes, three of Dothideomycetes, and two of Leotiomycetes), which are publicly available on the Internet, were investigated. The program Standalone BLAST 2.2.21 [49] was set up on a Windows XP system, and a local database was generated for each genome of the filamentous fungi. The complete genome of Neurospora crassa was split into individual gene sets. Each protein-coding gene was compared separately against each of the 30 genomes using Standalone BLASTN. An $E$-value cutoff of 0.1 was used to identify significant hits in this analysis. All BLAST analyses were run with default parameters in Standalone BLAST. The BLAST output files were parsed using PERL scripts, which generated a single line of output from each BLAST output file $[42,50]$. For each dataset, the individual lines were combined into a single file, and the file imported into a spreadsheet program, and then analyzed using Microsoft Office Excel (Windows XP). Certain specific groups of homologous sequences with a given $E$-value were aligned by ClustalX 1.81 [51].

\subsection{Primer design}

To design primers for PCR amplification and sequencing of the candidate markers, we used the corresponding sequences of gene fragments derived from whole-genome sequences of certain Sordariomycetes species including Fusarium graminearum, F. oxysporum, F. verticillioides, Magnaporthe grisea, $N$. crassa, Verticillium albo-atrum, and V. dahliae. A complete alignment was carried out using ClustalX [51] to find the conserved regions for primer design. Five primer pairs were designed using Primer Premier 5.0 [52], according to the main principles proposed by Compton [53], Dieffenbach and Dveksler [54], Goller et al. [55], Innis et al. [56], Saiki [57], and Sambrook and Russell [58].

\subsection{DNA amplification and sequencing}

Genomic DNA of each strain was isolated from mycelium grown on potato dextrose agar at room temperature for about two weeks [59]. The PCR reaction was performed on an ABI 2720 Thermal Cycler (Gene Co. Ltd., Foster City, California, USA). The $25 \mu \mathrm{L}$ reaction system comprised 16.25 $\mu \mathrm{L}$ of double distilled water, $2.5 \mu \mathrm{L}$ of $10 \times$ PCR buffer, $2 \mu \mathrm{L}$ of $\mathrm{MgCl}_{2}\left(25 \mathrm{mmol} \mathrm{L}{ }^{-1}\right), 1 \mu \mathrm{L}$ of each primer $\left(10 \mu \mathrm{mol} \mathrm{L}{ }^{-1}\right), 0.5 \mu \mathrm{L}$ of dNTP $\left(10 \mathrm{mmol} \mathrm{L}^{-1}\right.$ each $), 1.5 \mu \mathrm{L}$ of DNA template, and $0.25 \mu \mathrm{L}$ Taq DNA polymerase $(5 \mathrm{U}$ $\mu \mathrm{L}^{-1}$ ). The PCR primers used were newly designed in this study. The cycling conditions were an initial step of $5 \mathrm{~min}$ at $95^{\circ} \mathrm{C} ; 35$ cycles of $40 \mathrm{~s}$ at $94^{\circ} \mathrm{C}, 40 \mathrm{~s}$ at $54 / 56 / 52 / 62^{\circ} \mathrm{C}$ for $\mathrm{Hsp} 90 / \mathrm{AAC} / \mathrm{CDC} 48 / \mathrm{EF} 3$, respectively, and $40 \mathrm{~s}$ at $72^{\circ} \mathrm{C}$; followed by $10 \mathrm{~min}$ at $72^{\circ} \mathrm{C}$. The PCR products were verified by electrophoresis of $2.5 \mu \mathrm{L}$ products on a $1 \%$ agarose gel and staining with ethidium bromide. A molecular size marker was included to estimate length of the amplification 
Table 1 Materials used in this study

\begin{tabular}{|c|c|c|c|c|c|}
\hline \multirow{2}{*}{ Species } & \multirow{2}{*}{$\begin{array}{c}\text { Collection number } \\
\text { or source }^{\text {a) }}\end{array}$} & \multicolumn{4}{|c|}{ GenBank accession number } \\
\hline & & $H s p 90$ & $A A C$ & $C D C 48$ & EF3 \\
\hline \multirow[t]{2}{*}{ Albonectria rigidiuscula (Berk. \& Broome) Rossman \& Samuels } & HMAS 183135 & JN131641 & JN131694 & JN131748 & JN131802 \\
\hline & HMAS 183509 & JN131642 & JN131695 & JN131749 & JN131803 \\
\hline Chaetopsinectria chaetopsinae (Samuels) J. Luo \& W.Y. Zhuang & HMAS 76860 & JN131658 & JN131712 & JN131766 & JN131820 \\
\hline Corallomycetella repens (Berk. \& Broome) Rossman \& Samuels & AR 4659 & JN131615 & JN131668 & JN131722 & JN131776 \\
\hline Cosmospora coccinea Rabenh. & CBS 114050 & JN131609 & JN131662 & JN131716 & JN131770 \\
\hline C. episphaeria (Tode) Rossman \& Samuels & HMAS 99194 & JN131632 & JN131685 & JN131739 & JN131793 \\
\hline C. henanensis Y. Nong \& W.Y. Zhuang & HMAS 183528 & JN131635 & JN131688 & JN131742 & JN131796 \\
\hline C. meliopsicola (Henn.) Rossman \& Samuels & HMAS 86473 & JN131618 & JN131671 & JN131725 & JN131779 \\
\hline \multirow[t]{2}{*}{ Cosmospora sp. 1} & HMAS 76861 & JN131655 & JN131709 & JN131763 & JN131817 \\
\hline & CBS 122578 & JN131610 & JN131663 & JN131717 & JN131771 \\
\hline Cosmospora sp. 2 & GJS 85.205 & JN131649 & JN131703 & JN131757 & JN131811 \\
\hline C. vilior (Starbäck) Rossman \& Samuels & HMAS 183636 & JN131646 & JN131700 & JN131754 & JN131808 \\
\hline Gibberella zeae (Schwein.) Petch & HMAS 98297 & JN131631 & JN131684 & JN131738 & JN131792 \\
\hline \multirow[t]{3}{*}{ Haematonectria haematococca (Berk. \& Broome) Samuels \& Rossman } & HMAS 183156 & JN131636 & JN131689 & JN131743 & JN131797 \\
\hline & HMAS 183157 & JN131637 & JN131690 & JN131744 & JN131798 \\
\hline & HMAS 183514 & JN131643 & JN131696 & JN131750 & JN131804 \\
\hline \multirow[t]{2}{*}{ H. ipomoeae (Halst.) Samuels \& Nirenberg } & HMAS 188477 & JN131647 & JN131701 & JN131755 & JN131809 \\
\hline & HMAS 188475 & JN131648 & JN131702 & JN131756 & JN131810 \\
\hline Lanatonectria flavolanata (Berk. \& Broome) Samuels \& Rossman & HMAS 91516 & JN131622 & JN131675 & JN131729 & JN131783 \\
\hline L. flocculenta (Henn. \& E. Nyman) Samuels \& Rossman & HMAS 76873 & JN131653 & JN131707 & JN131761 & JN131815 \\
\hline Nectria australiensis Seifert & HMAS 83397 & JN131654 & JN131708 & JN131762 & JN131816 \\
\hline \multirow[t]{2}{*}{ N. cinnabarina (Tode) Fr. } & HMAS 98306 & JN131625 & JN131678 & JN131732 & JN131786 \\
\hline & HMAS 98311 & JN131629 & JN131682 & JN131736 & JN131790 \\
\hline \multirow[t]{2}{*}{ N. pseudotrichia (Schwein.) Berk. \& M.A. Curtis } & HMAS 97518 & JN131634 & JN131687 & JN131741 & JN131795 \\
\hline & HMAS 183560 & & JN131699 & JN131753 & JN131807 \\
\hline \multirow[t]{3}{*}{ Neonectria castaneicola (W. Yamam. \& Oyasu) Tak. Kobay. \& Hirooka } & HMAS 76865 & JN131656 & JN131710 & JN131764 & JN131818 \\
\hline & HMAS 83369 & JN131657 & JN131711 & JN131765 & JN131819 \\
\hline & HMAS 183542 & JN131640 & JN131693 & JN131747 & JN131801 \\
\hline \multirow[t]{2}{*}{ N. confusa J. Luo \& W.Y. Zhuang } & HMAS 99197 & JN131624 & JN131677 & JN131731 & JN131785 \\
\hline & HMAS 99198 & JN131626 & JN131679 & JN131733 & JN131787 \\
\hline \multirow[t]{2}{*}{ N. discophora var. discophora (Mont.) Mantiri \& Samuels } & HMAS 98333 & JN131619 & JN131672 & JN131726 & JN131780 \\
\hline & HMAS 98327 & JN131621 & JN131674 & JN131728 & JN131782 \\
\hline \multirow[t]{3}{*}{ N. ditissimopsis P. Zhao, J. Luo \& W.Y. Zhuang } & HMAS 98328 & JN131627 & JN131680 & JN131734 & JN131788 \\
\hline & HMAS 99206 & JN131628 & JN131681 & JN131735 & JN131789 \\
\hline & HMAS 98329 & JN131630 & JN131683 & JN131737 & JN131791 \\
\hline N. hubeinensis W.Y. Zhuang, Y. Nong \& J. Luo & HMAS 98331 & JN131620 & JN131673 & JN131727 & JN131781 \\
\hline N. jungneri Henn. & GJS 08-233 & JN131607 & JN131660 & JN131714 & JN131768 \\
\hline N. major (Wollenw.) Castl. \& Rossman & HMAS 183184 & JN131639 & JN131692 & JN131746 & JN131800 \\
\hline \multirow[t]{2}{*}{ N. ramulariae Wollenw. } & CBS 182.36 & JN131612 & JN131665 & JN131719 & JN131773 \\
\hline & CBS 151.29 & JN131611 & JN131664 & JN131718 & JN131772 \\
\hline N. shennongjiana J. Luo \& W.Y.Zhuang & HMAS 183185 & JN131659 & JN131713 & JN131767 & JN131821 \\
\hline N. sinensis J. Luo \& W.Y. Zhuang & HMAS 183186 & JN131651 & JN131705 & JN131759 & JN131813 \\
\hline \multirow[t]{3}{*}{ N. veuillotiana (Sacc. \& Roum.) Mantiri \& Samuels } & HMAS 98332 & JN131623 & JN131676 & JN131730 & JN131784 \\
\hline & HMAS 99207 & JN131633 & JN131686 & JN131740 & JN131794 \\
\hline & GJS 91-116 & JN131650 & JN131704 & JN131758 & JN131812 \\
\hline \multirow[t]{2}{*}{ Pseudonectria pachysandricola B.O. Dodge } & CBS 476.92 & JN131616 & JN131669 & JN131723 & JN131777 \\
\hline & CBS 501.63 & JN131617 & JN131670 & JN131724 & JN131778 \\
\hline \multirow[t]{2}{*}{ P. rousseliana (Mont.) Wollenw. } & AR 2714 & JN131613 & JN131666 & JN131720 & JN131774 \\
\hline & CBS 114049 & JN131608 & JN131661 & JN131715 & JN131769 \\
\hline Rubrinectria olivacea (Seaver) Rossman \& Samuels & AR 4331 & JN131614 & JN131667 & JN131721 & JN131775 \\
\hline
\end{tabular}

a) CBS, Centraalbureau voor Schimmelcultures, Utrecht, The Netherlands; GJS, G.J. Samuels; HMAS, Herbarium of Mycology, Institute of Microbiology, Chinese Academy of Sciences, Beijing, China; AR, Amy Rossman. 
products. The obtained amplicons were purified by PCR Product Purification Kit (Biocolor BioScience \& Technology Company) and sequenced in both directions, using the same primers used for PCR amplification, on an ABI 3730 XL DNA Sequencer (SinoGenoMax Co., Ltd.). The sequencing reactions were performed according to the manufacturer's protocol.

The original forward and reverse sequences were assembled manually, aligned using ClustalX [51], and edited to adjust the aligned sequences by BioEdit 7.0 [60]. The non-alignable sequences for Hsp90, AAC, and CDC48 gene fragments were removed to decrease the influence of large gaps. No gaps were found in the EF3 gene.

\subsection{Comparison of intra- and inter-specific divergences}

The aligned sequences were input into DNAstar 7.1.0 (Lasergene, WI, USA) to calculate the similarity matrices. A visualization analysis tool, TaxonGap 2.4.1 [61], was used to illustrate the sequence divergences within and between species of the candidate markers for each of the 34 investigated species.

The intra- and inter-specific pairwise distances were calculated using the K2P model in MEGA 4.1 [62]. The frequency distributions of the intra- and inter-specific distances were analyzed to check the barcoding gap, i.e., the space between intra- and inter-specific distances [63], using Microsoft Office Excel.

\subsection{Success rates of test barcode sequence acquisition}

The success rates of PCR amplification and sequencing were evaluated. PCR amplification was considered as successful when there was a single and clear band of the expected size on agarose gels. A high quality chromatogram counted as successful sequencing. The success rate of PCR amplification multiplied by that of sequencing determined the success rate of PCR amplification and sequencing.

\section{Results}

Thirty-one genomes of filamentous fungi were compared. Homologous sequences with $E$-values greater than $10^{-30}$ showed a high proportion of polymorphism, based on alignments using ClustalX [51]. Of the homologous sequences with $E$-values near or less than $10^{-100}$, the $H s p 90$, $A A C, C D C 48$, and $E F 3$ genes were randomly selected as candidate markers to investigate their feasibility in the identification of the 34 nectriaceous species. This is the first time that these gene fragments have been selected as candidate markers for the purpose of fungal DNA barcoding.

The designed primers are shown in Table 2. Degenerate primers were devised for the Hsp90,EF3, and CDC48 genes because variable bases were found at some positions.
PCR amplifications and sequencing were carried out successfully for all the selected gene fragments. The sequence lengths were 557-589 base pairs (bp) for $H s p 90$ gene, 551-607 bp for $A A C$ gene, 420-454 bp for CDC48 gene, and 501 bp for $E F 3$ gene.

To judge the suitability of a DNA barcode marker, the intra- and inter-specific sequence divergence is a very important criterion. Comparisons of the four candidate markers for each of the 34 Nectriaceae species were performed by TaxonGap [61]. The results are summarized in Figure 1. For each species, sequence similarity of the same gene within the same species was high; therefore, the relevant intra-specific variation (shown as grey bars in Figure 1) was low. For the $C D C 48$ and EF3 genes, the inter-specific variations were very similar, and are apparently higher than those for the $H s p 90$ and $A A C$ genes, and there was a clear gap between the maximum intra-specific variations and the minimum inter-specific variations. In the case of the Hsp 90 gene, the intra-specific variation for Nectria cinnabarina was very close to the inter-specific variation between Haematonectria haematococca and H. ipomoeae. Similarly, the intra-specific variation for Albonectria rigidiuscula was almost the same as the inter-specific variation between Cosmospora henanensis and Neonectria confusa when the $A A C$ gene was used, which indicates this gene may cause incorrect identification.

The frequency distributions of the intra- and inter-specific pairwise distances of the four candidates were analyzed to check the barcoding gap [63]. The results are shown in Figure 2. In the cases of the CDC48 and EF3 genes, the genetic distances within any single species did not exceed those among species, and a distinct gap was present between the inter- and intra-specific distances. In contrast, overlapping occurred when using the Hsp90 and $A A C$ genes, which indicated that they are not useful as barcode markers.

The ease of PCR amplification and nucleotide sequence acquisition is also important in evaluating a DNA barcode marker. Three of the four candidate markers were readily amplified and sequenced, with high success rates $(\geqslant 96.3 \%)$ (Table 3). However, for the CDC48 gene, additional primers were required.

Table 2 Primers used in this study

\begin{tabular}{cc}
\hline Primer name & Primer sequence $\left(5^{\prime} \rightarrow 3^{\prime}\right)$ \\
\hline Hsp90F & CATCATCAACACHGTCTACTCC \\
Hsp90R & KGAGATRAACTCGGAGTGCTTC \\
AACF & CCAACGTCATCCGTTACTT \\
AACR & ACCCTTGAAGAGAGACTTGA \\
CDCF & GCCGTCAACGATGARAAC \\
CDCR & CGACKACYTTGAACTCTACT \\
CDC1F & CGACTGCGATCCTCAAG \\
CDC1R & CCCTCGCAGTGAATGAC \\
EF3F & GACCACCATTGACTGGACCA \\
EF3R & TTGGAGGTRCCAGGGTACT \\
\hline
\end{tabular}




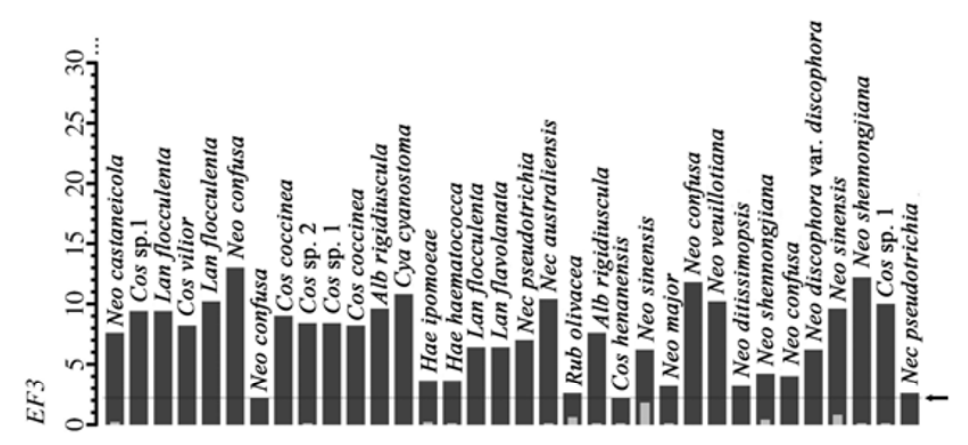

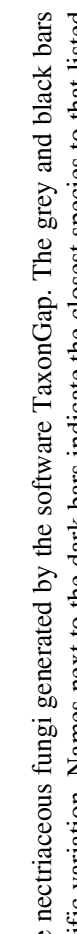
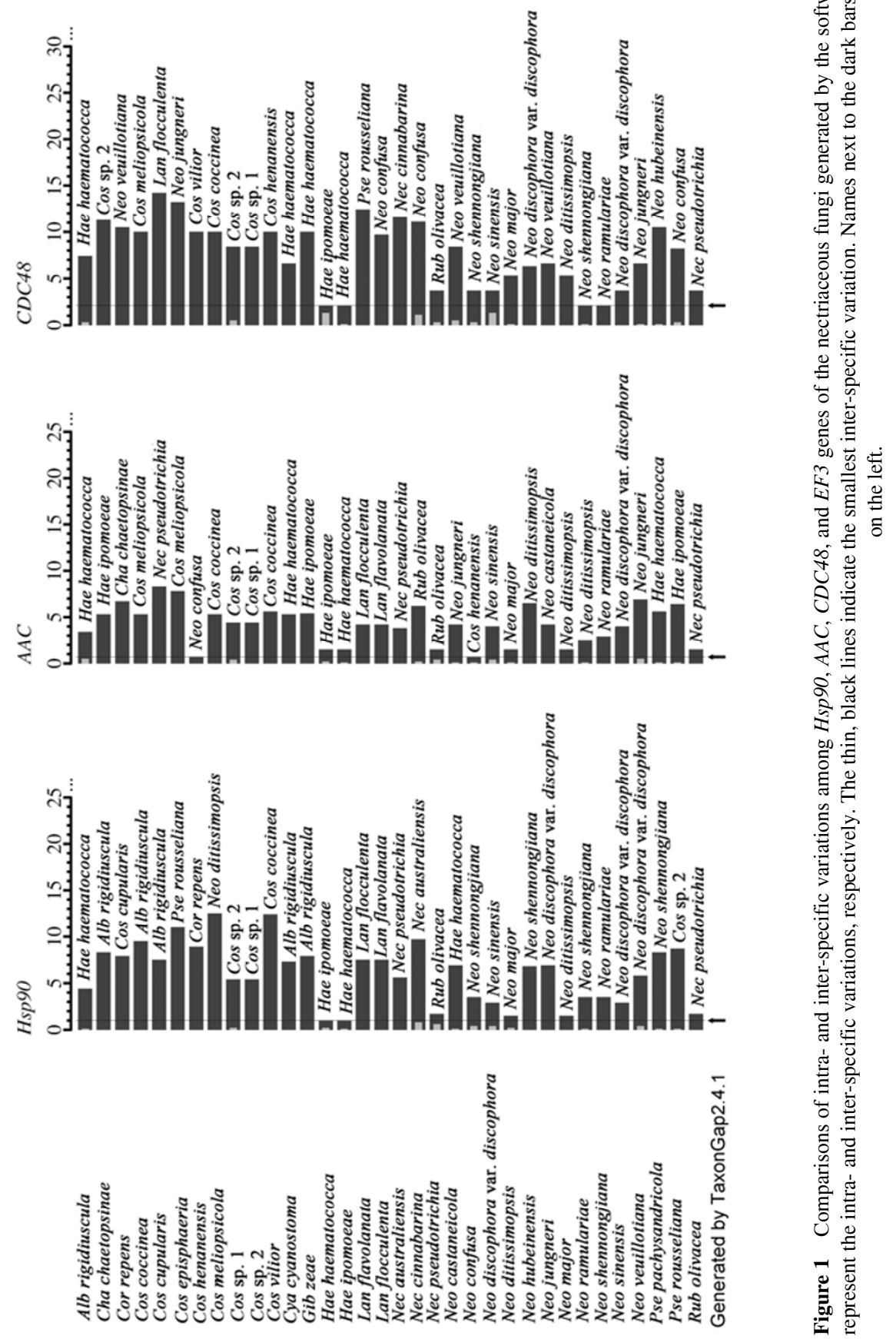
Table 3 Success rates of PCR and sequencing of Hsp90, AAC, CDC48, and EF3 genes of 34 species of Nectriaceae

\begin{tabular}{|c|c|c|c|c|}
\hline Candidate barcode & Hsp90 & $A A C$ & $C D C 48$ & $E F 3$ \\
\hline Efficiency of PCR amplification & $100 \%$ & $97.5 \%(79 / 81)$ & $87.7 \%(71 / 81)$ & $96.3 \%(78 / 81)$ \\
\hline Success rates of sequencing & $96.3 \%(78 / 81)$ & $100 \%$ & $95.8 \%(68 / 71)$ & $100 \%$ \\
\hline Success rate of PCR and sequencing & $96.3 \%$ & $97.5 \%$ & $84.0 \%$ & $96.3 \%$ \\
\hline
\end{tabular}

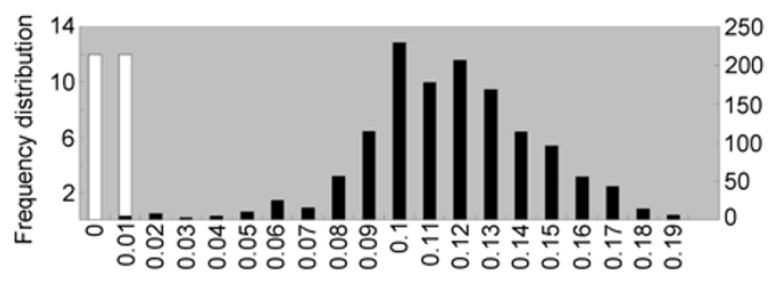

Hsp90 pairwise distance
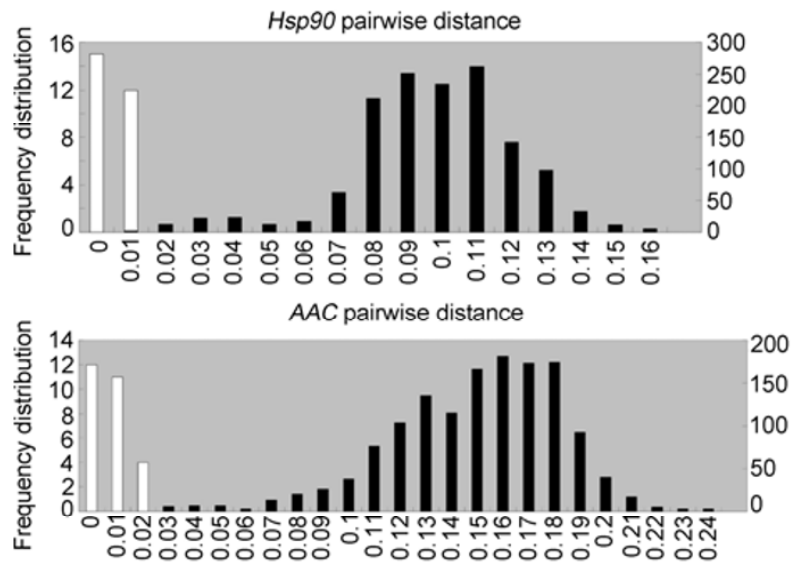

CDC48 pairwise distance

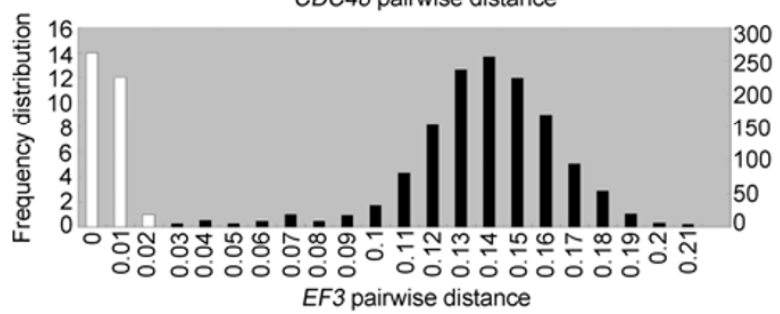

Figure 2 Comparisons of frequency distribution of intra- and interspecific pairwise distances among $H s p 90, A A C, C D C 48$, and $E F 3$ genes for the nectriaceous fungi generated with MEGA and Excel. The intra- and inter-specific distances are shown as white and black bars, respectively.

\section{Discussion}

\subsection{Selection of genes for DNA barcoding}

$E$-value is a parameter that describes the number of hits one can "expect" to see by chance when searching a database of a particular size [64]. Following the study by Fitzpatrick et al. [36], the top BLAST hits longer than 300 nucleotides were retained as putative open reading frames for further analysis. There has been some discussion concerning the statistical significance represented by $E$-value. Pertsemlidis and Fondon [65] and Zeng et al. [66] treated $E$-values less than 0.1 as a measure of statistical significance, while Pearson [67] suggested 0.02 as the boundary measurement. $E$-values below $10^{-5}$ are often considered to represent ho- mology [42,68-71]. In the present analysis, an $E$-value cutoff of 0.1 was first chosen to identify significant hits. Our results indicated that a threshold of $10^{-5}$ is better than 0.1 for searching for homologs among the fungi studied. Variability of the obtained homologous sequences was analyzed, based on alignment using ClustalX [51], to find the candidate markers. The result indicated that relatively conserved homologous sequences with $E$-values around or less than $10^{-100}$ may be suitable as candidate markers. As a result, four genes were selected as candidate markers.

Non-coding regions, such as the ITS, often have insufficient phylogenetic information to unequivocally identify closely related species in some genera of Ascomycota $[29,31,72,73]$. In contrast, protein-coding genes have higher information contents [74]. Accordingly, protein-coding DNA sequences might represent better candidates for fungal DNA barcoding.

\subsection{Evaluation of the candidate DNA markers}

Many criteria have been used to determine an ideal DNA barcode, such as a short fragment, universally used, having adequate variations among species, and conserved within a species, exhibiting a high degree of species resolution $[19,75]$. Sequence variations, frequency distribution of intra- and inter-specific pairwise distances, and easiness of sequence acquisition were treated as essential.

The Hsp90, AAC, CDC48, and $E F 3$ genes were tested for their feasibility as a DNA barcode for the nectriaceous fungi. The single copy gene $E F 3$ encoding the elongation factor 3 is a unique, essential, and soluble component of the translational system in fungi [76-78]. Our study presents a strong case for the partial EF3 gene being the most promising DNA barcode for this group. First, it exhibits the smallest sequence divergence within an individual species and a maximal separation among species. As calculated by TaxonGap [61], all the inter-specific variations were greater than the intra-specific variations, and a clear gap existed between them (Figure 1). This was further substantiated by the frequency distribution of the intra- and inter-specific pairwise distances calculated using MEGA [62] and Microsoft Office Excel. Its smallest inter-specific distance was $3.19 \%$, and the largest intra-specific distance was $1.79 \%$; thus, EF3 appeared to possess the appropriate intra- and inter-specific variations. No overlapping occurred between the intra- and inter-specific pairwise distances (Figure 2). Secondly, the partial EF3 gene lacks an intron and is relatively easy to obtain. Its PCR amplification and sequencing 
success rate reached $96.3 \%$, which was slightly lower than that of the $A A C$ gene $(97.5 \%)$ (Table 3 ).

The $C D C 48$ gene exists as a single copy per haploid genome [79]. Its encoded protein plays an essential role in cell proliferation, cell cycle progression, and ATP-dependent fusion of endoplasmic reticular membranes [80,81]. Determination of genetic divergence using two different methods confirmed that the CDC48 region possesses a good sequence divergence within and among species, which is equally high as that shown by the EF3 gene. An obvious boundary occurred between the intra- and inter-specific pairwise distances (Figure 2). However, it had a lower PCR and sequencing success rate $(84 \%$, Table 3$)$ when using a single pair of primers. Additional primers (CDC1F and CDC1R) were required to reach a higher success rate (Table 2). The Hsp90 protein plays a key role in signal transduction, cell cycle control, protein folding, protein degradation, cell signaling, and morphological evolution [82]. The nuclear gene $H s p 90$ is a single-copy gene and usually contains multiple introns $[83,84]$. It is highly conserved and extensively used in phylogenetic analyses [85-87]. In this study, although it had a high PCR and sequencing success rate (96.3\%) (Table 3), it cannot separate the intra- and inter-specific variations adequately (Figure 1), which influences its function as a barcode.

$A A C$ occurs as a single copy in the genome [88]. The protein is located on the inner membrane of the mitochondria and catalyses the exchange diffusion of ADP and ATP [89]. Our study showed that this gene had the highest PCR and sequencing success rate $(97.5 \%)$ (Table 3$)$. However, it showed a relatively low inter-specific variation leading to inaccurate identification of species (Figure 1).

Our results indicate that the partial $E F 3$ gene meets the requirements for a good DNA barcode. CDC48 gene possessed good sequence variations among species, but the PCR and sequencing success rate was relatively low. The $H$ sp90 and AAC genes had high PCR and sequencing success rates, while overlapping occurred between the intraand inter-specific distances, which may lead to misidentification. Compared with $\beta$-tubulin, which was previously suggested as a possible DNA barcode for the nectriaceous fungi [29], the sequence acquisition of $E F 3$ gene is easier.

Recently, Robert et al. [44] devised an approach to locate potential barcode markers from fungal genomes. Lewis et al. [45] managed to identify a barcode gene using a taxonomy-aware processing pipeline. Their results indicated that genome-mining has a potential use in fungal DNA barcoding. Our study may represent the first step towards selecting DNA barcodes from fungal whole-genome comparisons. With the increasing availability of genome datasets, we believe that comparative genomics will play an essential role in DNA barcoding.

This work was supported by the National Natural Science Foundation of China (Grant No. 31070015), the Special Project for Fundamental Re- search (Grant No. 2006FY120100) from Ministry of Science and Technology of China, and the Knowledge Innovation Program of Chinese Academy of Sciences (Grant No. KSCX2-EW-J-6). We are very grateful to Prof. Tom Hsiang for his review of the manuscript and language corrections, and to Dr. Zheng HuanDi for technical help.

1 Stockinger H, Krüger M, Schüßler A. DNA barcoding of arbuscular mycorrhizal fungi. New Phytol, 2010, 187: 461-474

2 Armstrong K F, Ball S L. DNA barcodes for biosecurity: invasive species identification. Phil Trans R Soc B, 2005, 360: 1813-1823

3 Ball S L, Armstrong K F. DNA barcodes for insect pest identification a test case with tussock moths (Lepidoptera: Lymantriidae). Can J For Res, 2006, 36: 337-350

4 Besansky N J, Severson D W, Ferdig M T. DNA barcoding of parasites and invertebrate disease vectors: what you don't know can hurt you. Trends Parasitol, 2003, 19: 545-546

5 Bucklin A, Steinke D, Blanco-Bercial L. DNA barcoding of marine metazoa. Annu Rev Mar Sci, 2011, 3: 471-508

6 Eaton M J, Meyers G L, Kolokotronis S O, et al. Barcoding bushmeat: molecular identification of Central African and South American harvested vertebrates. Conserv Genet, 2010, 11: 1389-1404

7 Hebert P D, Cywinska A, Ball S L, et al. Biological identifications through DNA barcodes. Proc R Soc Lond, 2003, 270: 313-321

8 Lowenstein $\mathrm{J} \mathrm{H}$, Amato G, Kolokotronis S O. The real maccoyii: identifying tuna sushi with DNA barcodes - contrasting characteristic attributes and genetic distances. PLoS ONE, 2009, 4: e7866

9 Steinke D, Zemlak T S, Boutillier J A, et al. DNA barcoding of Pacific Canada's fishes. Mar Biol, 2009, 156: 2641-2647

10 Steinke D, Zemlak T S, Hebert P D. Barcoding nemo: DNA-based identifications for the ornamental fish trade. PLoS ONE, 2009, 4: e6300

11 Stoeckle M Y, Hebert P D. Barcode of life. Sci Am, 2008, 299: 88

12 Valentini A, Pompanon F, Taberlet P. DNA barcoding for ecologists. Trends Ecol Evol, 2009, 24: 110-117

13 Boehme P, Amendt J, Disney R H, et al. Molecular identification of carrion-breeding scuttle flies (Diptera: Phoridae) using COI barcodes. Int J Legal Med, 2010, 124: 577-581

14 Feng Y W, Li Q, Kong L F, et al. DNA barcoding and phylogenetic analysis of Pectinidae (Mollusca: Bivalvia) based on mitochondrial COI and 16S rRNA genes. Mol Biol Rep, 2011, 38: 291-299

15 Francis C M, Borisenko A V, Ivanova N V, et al. The role of DNA barcodes in understanding and conservation of mammal diversity in Southeast Asia. PLoS ONE, 2010, 5: e12575

16 Hebert P D, Ratnasingham S, de Waard J R. Barcoding animal life: cytochrome c oxidase subunit 1 divergences among closely related species. Proc R Soc Lond B (Suppl), 2003, 270: S96-S99

17 Hebert P D, deWaard J R, Landry J F. DNA barcodes for 1/1000 of the animal kingdom. Biol Lett, 2009, 6: 359-362

18 Hebert P D, Stoeckle M Y, Zemlak T S, et al. Identification of birds through DNA barcodes. PLoS Biol, 2004, 2: e312

19 Hollingsworth P M, Forrest L L, Spouge J L, et al. A DNA barcode for land plants. Proc Natl Acad Sci USA, 2009, 106: 12794-12797

20 Zuo Y, Chen Z, Kondo K, et al. DNA barcoding of panax species. Planta Med, 2011, 77: 182-187

21 Chen S, Yao H, Han J, et al. Validation of the ITS2 region as a novel DNA barcode for identifying medicinal plant species. PLoS ONE, 2010, 5: e8613

22 Luo K, Chen S, Chen K, et al. Assessment of candidate plant DNA barcodes using the Rutaceae family. Sci China Life Sci, 2010, 53: 701-708

23 Cräutlein M, Korpelainen H, Pietiläinen M, et al. DNA barcoding: a tool for improved taxon identification and detection of species diversity. Biodivers Conserv, 2011, 20: 373-389

24 Schwarz P, Bretagne S, Gantier J C, et al. Molecular identification of zygomycetes from culture and experimentally infected tissues. J Clin Microbiol, 2006, 44: 340-349

25 Druzhinina I S, Kopchinskiy A G, Komoń M, et al. An oligonucleotide barcode for species identification in Trichoderma and Hypocrea. 
Fungal Genet Biol, 2005, 42: 813-828

26 Frøslev T G, Jeppesen T S, Læssøe T, et al. Molecular phylogenetics and delimitation of species in Cortinarius section Calochroi (Basidiomycota, Agaricales) in Europe. Mol Phylogenet Evol, 2007, 44: 217-227

27 Feau N, Vialle A, Allaire M, et al. Fungal pathogen (mis-) identifications: A case study with DNA barcodes on Melampsora rusts of aspen and white poplar. Mycol Res, 2009, 113: 713-724

28 Roe A D, Rice A V, Bromilow S E, et al. Multilocus species identification and fungal DNA barcoding: insights from blue stain fungal symbionts of the mountain pine beetle. Mol Ecol Resour, 2010, 10: 946-959

29 Zhao P, Luo J, Zhuang W Y. Practice towards DNA barcoding of the nectriaceous fungi. Fungal Diversity, 2011, 46: 183-191

30 Geiser D M, Jiménez-Gasco M, Kang S, et al. FUSARIUM-ID v.1.0: A DNA sequence database for identifying Fusarium. Eur J Plant Pathol, 2004, 110: 473-479

31 O'Donnell K, Cigelnik E. Two divergent intragenomic rDNA ITS2 types within a monophyletic lineage of the fungus Fusarium are nonorthologous. Mol Phylogenet Evol, 1997, 7: 103-116

32 Seifert K A. Progress towards DNA barcoding of fungi. Mol Ecol Resour, 2009, 9: 83-89

33 Goffeau A, Barrell B G, Bussey H, et al. Life with 6000 genes. Science, 1996, 274: 563-567

34 Ma L J, Fedorovab N D. A practical guide to fungal genome projects: strategy, technology, cost and completion. Mycology, 2010, 1: 9-24

35 Cornell M J, Alam I, Soanes D M, et al. Comparative genome analysis across a kingdom of eukaryotic organisms: specialization and diversification in the fungi. Genome Res, 2007, 17: 1809-1822

36 Fitzpatrick D A, Logue M E, Stajich J E, et al. A fungal phylogeny based on 42 complete genomes derived from supertree and combined gene analysis. BMC Evol Biol, 2006, 6: 99

37 Moran G P, Coleman D C, Sullivan D J. Comparative genomics and the evolution of pathogenicity in human pathogenic fungi. Eukaryot Cell, 2011, 10: 34-42

38 Soanes D M, Alam I, Cornell M, et al. Comparative genome analysis of filamentous fungi reveals gene family expansions associated with fungal pathogenesis. PLoS ONE, 2008, 3: e2300

39 Firon A, d'Enfert C. Identifying essential genes in fungal pathogens of humans. Trends Microbiol, 2002, 10: 456-462

40 Jiang B, Bussey H, Roemer T. Novel strategies in antifungal lead discovery. Curr Opin Microbiol, 2002, 5: 466-471

41 Parkinson T. The impact of genomics on anti-infectives drug discovery and development. Trends Microbiol, 2002, 10: S22-S26

42 Hsiang T, Baillie D L. Comparison of the yeast proteome to other fungal genomes to find core fungal genes. J Mol Evol, 2005, 60: 475-483

43 Liti G, Louis E J. Yeast genome evolution and comparative genomics. Ann Rev Microbiol, 2005, 59: 135-153

44 Robert V, Szöke S, Eberhardt U, et al. The quest for a general and reliable fungal DNA barcode. Open Appl Inform J, 2011, 5: 45-61

45 Lewis C T, Bilkhu S, Robert V, et al. Identification of fungal DNA barcode targets and PCR primers based on Pfam protein families and taxonomic hierarchy. Open Appl Inform J, 2011, 5: 30-44

46 Hardison R C. Comparative Genomics. PLoS Biol, 2003, 1: e58

47 Rossman A Y, Samuels G J, Rogerson C T, et al. Genera of Bionectriaceae, Hypocreaceae and Nectriaceae (Hypocreales, Ascomycetes). Stud Mycol, 1999, 42: 1-248

48 Zhuang W Y. Taxonomy and related studies on the nectrioid fungi from China. Chin Bull Life Sci, 2010, 22: 1083-1085

49 Altschul S F, Gish W, Miller W, et al. Basic local alignment search tool. J Mol Biol, 1990, 215: 403-410

50 Hsiang T, Goodwin P H. Distinguishing plant and fungal sequences in ESTs from infected plant tissues. J Microbiol Methods, 2003, 54: 339-351

51 Thompson J D, Higgins D G, Gibson T J. CLUSTAL W: improving the sensitivity of progressive multiple sequence alignments through sequence weighting, position specific gap penalties and weight matrix choice. Nucleic Acids Res, 1994, 22: 4673-4680
52 Lalitha S. Primer Premier 5. Biotech Softw Internet Rep, 2000, 1: 270-272

53 Compton T. Degenerate primers for DNA amplification. In: Innis M A, Gelfand D H, Sninsky J J, et al., eds. PCR Protocols: A Guide to Methods and Applications. New York: Academic Press, 1990. 39-45

54 Dieffenbach C W, Dveksler G S. PCR Primer: a Laboratory Manual. New York: Cold Spring Harbor Press, 1995. 15-41

55 Goller S P, Gorfer M, Mach R L, et al. Gene cloning using PCR. In: Bridge P D, Arora D K, Reddy C A, et al., eds. Applications of PCR in Mycology. Wallingford: CAB International, 1998. 21-45

56 Innis M A, Gelfand D H. Optimization of PCRs. In: Innis M A, Gelfand D H, Sninsky J J, et al., eds. PCR Protocols: A Guide to Methods and Applications. New York: Academic Press, 1990. 3-12

57 Saiki R K. Amplification of genomic DNA. In: Innis M A, Gelfand D H, Sninsky J J, et al., eds. PCR Protocols: A Guide to Methods and Applications. New York: Academic Press, 1990. 13-20

58 Sambrook J, Russell D W. Molecular cloning: a laboratory manual. 3rd ed. New York: Cold Spring Harbor Press, 2001. 1.31-1.38

59 Wang L, Zhuang W Y. Designing primer sets for amplification of partial calmodulin genes from penicillia. Mycosystema, 2004, 23: 466-473

60 Hall T A. BioEdit: a user-friendly biological sequence alignment editor and analysis program for Windows 95/98/NT. Nucleic Acids Symp Ser, 1999, 41: 95-98

61 Slabbinck B, Dawyndt P, Martens M, et al. TaxonGap: a visualisation tool for intra- and inter-species variation among individual biomarkers. Bioinformatics, 2008, 24: 866-867

62 Tamura K, Dudley J, Nei M, et al. MEGA4: Molecular Evolutionary Genetics Analysis (MEGA) software version 4.0. Mol Biol Evol, 2007, 24: 1596-1599

63 Meyer C P, Paulay G. DNA barcoding: error rates based on comprehensive sampling. PLoS Biol, 2005, 3: e422

64 Hsiang T, Baillie D L. Recent progress, developments, and issues in comparative fungal genomics. Can J Plant Pathol, 2004, 26: 19-30

65 Pertsemlidis A, Fondon J W. Having a BLAST with bioinformatics (and avoiding BLASTphemy). Genome Biol, 2002, 2: 1-10

66 Zeng Z Q, Zhao F Y, Hsiang T, et al. Comparison of genomes between Aspergillus nidulans and 30 filamentous ascomycetes. Yi Chuan, 2010, 32: 1195-1202

67 Pearson W R. Empirical statistical estimates for sequence similarity searches. J Mol Evol, 1998, 276: 71-84

68 Keon J, Bailey A, Hargreaves J. A group of expressed cDNA sequences from the wheat fungal leaf blotch pathogen, Mycosphaerella graminicola (Septoria tritici). Fungal Genet Biol, 2000, 29: 118-133

69 Kruger W M, Pritsch C, Chao S, et al. Functional and comparative bioinformatic analysis of expressed genes from wheat spikes infected with Fusarium graminearum. Mol Plant Microbe Interact, 2002, 15: 445-455

70 Thomas S W, Glaring M A, Rasmussen S W, et al. Transcript profiling in the barley mildew pathogen Blumeria graminis by serial analysis of gene expression (SAGE). Mol Plant Microbe Interact, 2002, 15: 847-856

71 Thomas S W, Rasmussen S W, Glaring M A, et al. Gene identification in the obligate fungal pathogen Blumeria graminis by expressed sequence tag analysis. Fungal Genet Biol, 2001, 33: 195-211

72 Schubert K, Groenewald J Z, Braun U, et al. Biodiversity in the Cladosporium herbarum complex (Davidiellaceae, Capnodiales), with standardisation of methods for Cladosporium taxonomy and diagnostics. Stud Mycol, 2007, 58: 105-156

73 Skouboe P, Frisvad J C, Taylor J W, et al. Phylogenetic analysis of nucleotide sequences from the ITS region of terverticillate Penicillium species. Mycol Res, 1999, 103: 873-881

74 Liu Y J, Whelen S, Hall B D. Phylogenetic relationships among Ascomycetes: evidence from an RNA polymerase II subunit. Mol Biol Evol, 1999, 16: 1799-1808

75 Taberlet P, Coissac E, Pompanon F, et al. Power and limitations of the chloroplast trnL (UAA) intron for plant DNA barcoding. Nucleic Acids Res, 2007, 35: e14

76 Myers K K, Fonzi W A, Sypherd P S. Isolation and sequence analysis 
of the gene for translation elongation factor 3 from Candida albicans. Nucleic Acids Res, 1992, 20: 1705-1710

77 Qin S L, Moldave K, McLaughlin C S. Isolation of the yeast gene encoding elongation factor 3 for protein synthesis. J Biol Chem, 1987, 262: 7802-7807

78 Ypma-Wong M F, Fonzi W A, Sypherd P S. Fungus-specific translation elongation factor 3 gene present in Pneumocystis carinii. Infect Immun, 1992, 60: 4140-4145

79 Fröhlich K U, Fries H W, Rüdiger M, et al. Yeast cell cycle protein CDC48p shows full-length homology to the mammalian protein VCP and is a member of a protein family involved in secretion, peroxisome formation, and gene expression. J Cell Biol, 1991, 114: $443-453$

80 Imamura S, Ojima N, Yamashita M. Cold-inducible expression of the cell division cycle gene CDC48 and its promotion of cell proliferation during cold acclimation in zebrafish cells. FEBS Lett, 2003, 549: 14-20

81 Latterich M, Fröhlich K U, Schekman R. Membrane fusion and the cell cycle: Cdc48p participates in the fusion of ER membranes. Cell, 1995, 82: 885-893

82 Chen B, Piel W H, Gui L, et al. The HSP90 family of genes in the human genome: insights into their divergence and evolution. Ge- nomics, 2005, 86: 627-637

83 Farrelly F W, Finkelstein D B. Complete sequence of the heat shock-inducible HSP90 gene of Saccharomyces cerevisiae. J Biol Chem, 1984, 259: 5745-5751

84 Nageshan R K, Roy N, Hehl A B, et al. Post-transcriptional repair of a split heat shock protein 90 gene by mRNA trans-splicing. J Biol Chem, 2011, 286: 7116-7122

85 Gupta R S. Phylogenetic analysis of the $90 \mathrm{kD}$ heat shock family of protein sequences and an examination of the relationship among animals, plants, and fungi species. Mol Biol Evol, 1995, 12: 1063-1073

86 Gupta R S. Protein phylogenies and signature sequences: A reappraisal of evolutionary relationships among archaebacteria, eubacteria, and eukaryotes. Mol Biol Rev, 1998, 62: 1435-1491

87 Stechmann A, Cavalier-Smith T. Evolutionary origins of Hsp90 chaperones and a deep paralogy in their bacterial ancestors. J Eukaryot Microbiol, 2004, 51: 364-373

88 Arends H, Sebald W. Nucleotide sequence of the cloned mRNA and gene of the ADP/ATP carrier from Neurospora crassa. EMBO J, 1984, 3: 377-382

89 Zimmerman R, Paluch U, Sprinzl M, et al. Cell-free synthesis of the mitochondrial ADP/ATP carrier protein of Neurospora crassa. Eur J Biochem, 1979, 99: 247-252

Open Access This article is distributed under the terms of the Creative Commons Attribution License which permits any use, distribution, and reproduction in any medium, provided the original author(s) and source are credited. 